\title{
An assessment of uncertainties in using volume-area modelling for computing the twenty-first century glacier contribution to sea-level change
}

\author{
A. B. A. Slangen and R. S. W. van de Wal \\ Institute for Marine and Atmospheric research Utrecht, Utrecht University, \\ Princetonplein 5, 3584 CC Utrecht, The Netherlands \\ Received: 23 May 2011 - Published in The Cryosphere Discuss.: 1 June 2011 \\ Revised: 17 August 2011 - Accepted: 22 August 2011 - Published: 24 August 2011
}

\begin{abstract}
A large part of present-day sea-level change is formed by the melt of glaciers and ice caps (GIC). This study focuses on the uncertainties in the calculation of the GIC contribution on a century timescale. The model used is based on volume-area scaling, combined with the mass balance sensitivity of the GIC. We assess different aspects that contribute to the uncertainty in the prediction of the contribution of GIC to future sea-level rise, such as (1) the volume-area scaling method (scaling factor), (2) the glacier data, (3) the climate models, and (4) the emission scenario. Additionally, a comparison of the model results to the 20th century GIC contribution is presented.

We find that small variations in the scaling factor cause significant variations in the initial volume of the glaciers, but only limited variations in the glacier volume change. If two existing glacier inventories are tuned such that the initial volume is the same, the GIC sea-level contribution over $100 \mathrm{yr}$ differs by $0.027 \mathrm{~m}$ or $18 \%$. It appears that the mass balance sensitivity is also important: variations of $20 \%$ in the mass balance sensitivity have an impact of $17 \%$ on the resulting sea-level projections. Another important factor is the choice of the climate model, as the GIC contribution to sea-level change largely depends on the temperature and precipitation taken from climate models. Connected to this is the choice of emission scenario, used to drive the climate models. Combining all the uncertainties examined in this study leads to a total uncertainty of $0.052 \mathrm{~m}$ or $35 \%$ in the GIC contribution to global mean sea level. Reducing the variance in the climate models and improving the glacier inventories will sig-
\end{abstract}

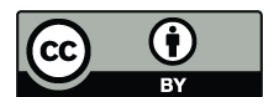

Correspondence to: A. B. A. Slangen (a.slangen@uu.nl) nificantly reduce the uncertainty in calculating the GIC contributions, and are therefore crucial actions to improve future sea-level projections.

\section{Introduction}

Sea-level change is an important issue in the field of climate change. Currently, the largest contributions to sea-level change are the addition of mass through land ice melt and the thermal expansion of the ocean water (Bindoff et al., 2007). The land ice contribution consists of mass loss from the two large ice sheets (Greenland and Antarctica) and the glaciers and ice caps (GIC) outside the ice sheets. Both are important contributions and need further consideration for future sealevel predictions. Here we focus on the contribution of the GIC.

There are several methods to calculate the evolution of GIC in time and their response to climatic changes. A physically based approach would be to use flow line models forced by appropriate mass balance schemes. However, these require detailed input, such as glacier bed topography, ice thickness and knowledge of the microclimate, which is available for only a few glaciers around the world. It is therefore not possible to use this approach on a global scale yet. As an alternative, scaling methods are used, which are based on relatively simple geometric features of glaciers, such as the length or the area, and their relation to the volume of the glacier. Examples are volume-length scaling (Oerlemans et al., 2007; Leclercq et al., 2011), volume-area scaling (e.g. Bahr et al., 1997; Van de Wal and Wild, 2001), or volumearea-length scaling (Radić and Hock, 2011). These methods

Published by Copernicus Publications on behalf of the European Geosciences Union. 
use empirical relations derived for a small set of glaciers, which are extended to a global scale. This is supported by theoretical analyses by Bahr et al. (1997). Additionally, the required mass balance changes may be obtained by using seasonal sensitivity characteristics (Oerlemans and Reichert, 2000), by modelling the changes in mass balance profiles (Raper and Braithwaite, 2006), by applying a simplified mass balance model (Radić and Hock, 2011), or by using a relation between mass balance sensitivity and precipitation (e.g. Gregory and Oerlemans, 1998; Van de Wal and Wild, 2001). An even more direct way to obtain a global estimate of GIC changes is to use a scaling relation between global temperature change and total ice volume without area size classes or latitudinal dependence, as applied in the Intergovernmental Panel on Climate Change (IPCC) Fourth Assessment Report (AR4) (see Appendix 10.A.3 in Meehl et al., 2007b).

Over the past few years, several studies have presented estimates for the twenty-first century GIC sea-level contribution using different methods. IPCC AR4 projected a contribution of $0.08-0.15 \mathrm{~m}$ sea-level equivalent (SLE) for the A1B scenario (Meehl et al., 2007b), based on a range of climate models and three different values for the initial volume of all glaciers. As a follow-up on IPCC AR4, Meier et al. (2007) estimated a GIC contribution of 0.1-0.25 m SLE by 2100 , where the range originates from two assumptions for the acceleration of ice loss. Another estimate was presented by Pfeffer et al. (2008), who found a GIC contribution of $0.17-0.55 \mathrm{~m} \mathrm{SLE}$ by 2100 , based on kinematically constrained scenarios. Bahr et al. (2009) used the accumulation area ratio (AAR) and calculated that GIC contribute $0.18 \mathrm{~m} \mathrm{SLE}$ before they are in balance with the current climate. However, none of these studies provide regional estimates of GIC volume changes. The latter is done in a recent study by Radić and Hock (2011), who find a global mean contribution of $0.124 \pm 0.037 \mathrm{~m}$ SLE. They use volume-arealength scaling to calculate regional glacier mass changes in response to climate model projections. Another study that provides regional estimates is Slangen et al. (2011), who use volume-area scaling and arrive at a GIC contribution of $0.17 \pm 0.04 \mathrm{~m}$ SLE.

The current study does not aim at improving the estimate of the GIC sea-level contribution as most of the above studies do, but at providing insight into the uncertainties of the GIC contribution.

The model used here is based on the volume-area scaling method, which builds on concepts developed by Bahr et al. (1997) and was applied for sea-level projections by Van de Wal and Wild (2001) and Slangen et al. (2011). The model uses the volume-area relation in combination with a relation for the mass balance sensitivity of the glaciers and the amount of precipitation. The present study uses the same approach and data as the Slangen et al. (2011) study, with the only difference that Antarctic glaciers are excluded here to enable a comparison to the older inventory used by Van de Wal and Wild (2001). This leads to a lower value for the total GIC contribution to sea-level change than in Slangen et al. (2011).

Details of the model set-up and the data used in this study are presented in Sect. 2. A comparison of the model results for the past GIC contribution and a description of the reference experiment is presented in Sect. 3. In Sect. 4, which forms the core of this paper, the sensitivity studies are described. We distinguish uncertainties related to the volumearea scaling method (Sect. 4.1), the glacier data (Sect. 4.2), the choice of climate model (Sect. 4.3), and the choice of emission scenario (Sect. 4.4). Finally, in Sect. 5, a summary of the findings in the previous sections is presented.

\section{Data and methods}

\subsection{The volume-area model}

The volume-area scaling method (e.g. Bahr et al., 1997; Van de Wal and Wild, 2001) assumes that the area of a glacier is proportional to its volume using a power law:

$V=c A^{\gamma}$,

where $c$ and $\gamma$ are scaling parameters. For glaciers, $\gamma$ is set to 1.375 (Bahr, 1997; Chen and Ohmura, 1990). For $c$, Van de Wal and Wild (2001) used a value of $0.12 \mathrm{~m}^{3-2 \gamma}$ to obtain a total GIC volume of $0.50 \mathrm{~m}$ sea-level equivalent (SLE) including GIC surrounding Antarctica and Greenland. Radić and Hock (2010) use a value of $0.2055 \mathrm{~m}^{3-2 \gamma}$ and arrive at $0.60 \mathrm{~m}$ SLE for their glacier inventory. Here we vary $c$ from 0.05 to $0.30 \mathrm{~m}^{3-2 \gamma}$ in the sensitivity analysis (Sect. 4.1.2), and use $0.2055 \mathrm{~m}^{3-2 \gamma}$ as the reference value. For ice caps, $\gamma$ is set to 1.25 and $c$ to $1.7026 \mathrm{~m}^{3-2 \gamma}$, assuming an ice cap with a circular base (Paterson, 1994). These ice cap values are kept constant throughout the study, because variations in $c$ of $\pm 25 \%$ were found to lead to very small variations of $\pm 0.5 \%$ in the sea-level contribution.

The specific glacier model used in this study is developed by Van de Wal and Wild (2001), and it calculates the evolution of GIC in time given a certain initial glacier inventory. The volume change of all GIC is calculated while accounting for the change of glacier area $(A)$ in time $(t)$, temperature changes $(\Delta T)$ and precipitation changes $(\Delta P)$, by applying the following expression:

$$
\begin{aligned}
& \frac{d V}{d t}=\sum_{j=1}^{n} \sum_{k=1}^{m} A(j, k, t) . \\
& \left\{\Delta T_{\mathrm{s}}(j, t) \frac{d B_{P(j, t)}}{d T_{\mathrm{S}}}+\Delta T_{\mathrm{ns}}(j, t) \frac{d B_{P(j, t)}}{d T_{\mathrm{ns}}}+\Delta P(j, t)\right\} .
\end{aligned}
$$

In Eq. (2), glacier area $A$ is summed over $n$ regions and $m$ size bins. $d T_{\mathrm{S}}$ are local summer temperature variations (summer is JJA in Northern Hemisphere, DJF in Southern Hemisphere), and $d T_{\mathrm{ns}}$ are non-summer temperature variations. The mass balance sensitivity is a function of the local 
Table 1. Regions and initial volume in $1990\left(\mathrm{~km}^{3}\right)$ used in this study.

\begin{tabular}{llrlr}
\hline This study & Region name (R10) & $\begin{array}{r}\text { Volume } \\
\left(\mathrm{km}^{3}\right)\end{array}$ & Region name, number (W01) & $\begin{array}{r}\text { Volume } \\
\left(\mathrm{km}^{3}\right)\end{array}$ \\
\hline 1 Arctic Canada & Arctic Canada & 81943 & North Canada, 1-6 & 63149 \\
2 Alaska & Alaska/W. Canada/W. US & 30519 & Alaska/Rocky Mountains, 7-30 & 21802 \\
3 Iceland & Iceland & 4558 & Iceland, 53-57 & 2191 \\
4 Svalbard & Svalbard & 10199 & Svalbard, 58 & 6995 \\
5 Scandinavia & Scandinavia & 222 & Scandinavia, 62-63 & 155 \\
6 Russian Arctic & Franz Jos./N. Zemlya/S. Zemlya & 17658 & Franz Josef, 59-61 & 11134 \\
7 East Russia & North and East Asia & 168 & East Russia, 88-93 & 351 \\
8 Central Europe & Central Europe & 192 & Central Europe, 64-65 & 130 \\
9 South Russia & Caucasus & 88 & South Russia, 66-69 & 374 \\
10 Central Asia & High Mountain Asia & 12536 & Central Asia, 70-87 & 24514 \\
11 South America & South America I/II & 7570 & South America, 31-52 & 14873 \\
12 Africa & - & 0 & South Africa, 94-96 & 0.2 \\
13 New Zealand & New Zealand & 82 & New Zealand, 98-100 & 219 \\
14 Greenland & Greenland & 16099 & Greenland, 101-135 & 36398 \\
\hline
\end{tabular}

annual precipitation $P$ according to the relations from Zuo and Oerlemans (1997) (Z97):

$\frac{d B}{d T_{\mathrm{s}}}=-0.259 P^{0.427}$

$\frac{d B}{d T_{\mathrm{ns}}}=-0.387 P^{0.683}+0.259 P^{0.427}$

Temperature $(T)$ and precipitation $(P)$ are taken from Atmosphere-Ocean General Circulation Models (AOGCMs) (Meehl et al., 2007a) using the nearest neighbour approach. This introduces an uncertainty in the GIC contribution to sealevel change which will be further treated in Sect. 4. Both $T$ and $P$ are time dependent, which implies that the mass balance sensitivity itself changes over time as well.

All values for initial volume $\left(V_{\mathrm{i}}\right)$ and the GIC contribution to sea-level change $(\delta V)$ shown in the next sections are, unless explicitly mentioned, mean values of calculations with temperature and precipitation scenarios obtained from 12 AOGCMs (Meehl et al., 2007a). The set of AOGCMs will be referred to as a model ensemble, and will be more thoroughly described in Sect. 2.3.

The imbalance of the GIC with climate is accounted for by starting the calculations in 1865 , and applying a global temperature increase of $0.7^{\circ} \mathrm{C} 100 \mathrm{yr}^{-1}$ over the period $1865-$ 1990 (Trenberth et al., 2007). The importance of the imbalance of the GIC with climate is tested in Sect. 4.1.3, by applying data of Z97, which cover the period 1865-1990. For this reason we adopt 1990 as the starting year for the future contribution. The starting volume and area in 1865 are calculated iteratively, such that the modelled volume and area in 1990 agree with the glacier inventory. The model calculations are continued for another $100 \mathrm{yr}$ after 1990 , which results in a total of 225 modelled years. Future volume changes are therefore defined as the difference between 1990 and 2090.

\subsection{Two glacier inventories}

In this study, two glacier inventories are used, in order to estimate the uncertainty related to the choice of inventory. The first and default glacier inventory is an extended version of the WGI-XF (Cogley, 2009a), which has a World Glacier Inventory core (WGI, National Snow and Ice Data Center, 1999, updated 2009), and is combined with Icelandic and Alaskan data (Radić and Hock, 2010). The GIC are divided into 19 large regions, of which two are located around Antarctica. As the second inventory (described below) does not contain any Antarctic data, the two Antarctic regions of this inventory will be excluded from this comparison. Of the remaining 17 regions, 7 regions have an incomplete glacier inventory. To complete these regions, an upscaling procedure is performed as described in Radić and Hock (2010). Then, to obtain the new number of glaciers per size bin, we divide the upscaled area by the average area in the size bin before upscaling. It is assumed that the entire upscaled area consists of glaciers, which slightly changes the ratio of glaciers and ice caps. However, tests show that this influence is negligibly small. We sort the remaining 17 regions into 14 regions as shown in Table 1. Using these 14 regions of Z97 facilitates a comparison of Radić and Hock (2010) data with the second glacier inventory. The total area in the Radic and Hock (2010) data set is $568709 \mathrm{~km}^{2}$. Each region has a size distribution in 18 size classes, ranging from $<2^{-3} \mathrm{~km}^{-2}$ to $2^{13}-2^{14} \mathrm{~km}^{-2}$. We will from now on refer to this glacier inventory as R10.

The second inventory used in this study also has a WGI core, but uses an older version than the R10 data set. Furthermore, the treatment of data-sparse regions differs from R10. This inventory consists of 135 regions, of which 100 regions are the main glaciated regions outside the two major 


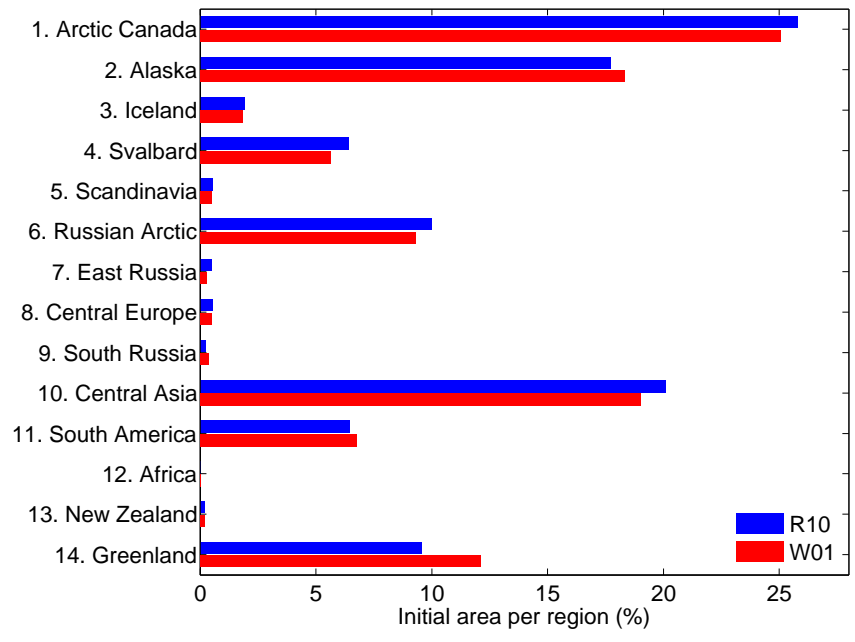

Fig. 1. Relative initial GIC area per region for the two glacier inventories.

ice sheets (Oerlemans, 1993, Z97), and 35 regions are located around the Greenland ice sheet (Van de Wal and Wild, 2001). The 135 regions are also merged into 14 large regions, as shown in Table 1. The total glaciated area in this data set is $597613 \mathrm{~km}^{2}$. For 41 of the 135 glaciated regions a size distribution is available in 15 size classes (from $2^{-6}-2^{-5} \mathrm{~km}^{-2}$ to $\geq 2^{9} \mathrm{~km}^{-2}$ ). For the 35 regions on Greenland it is assumed that all glaciers are in the largest possible size class. The remaining 59 regions are assigned the average size distribution of the 41 regions which have a size distribution. From now on we will refer to this glacier inventory as W01.

As the GIC contribution to sea level is dominated by the large size classes we prefer the R10 data set as the reference inventory, since it has a better subdivision of the large classes than the W01 data set. Nevertheless, we will also use the W01 data to show how differences in the inventory, upscaling and area binning contribute to the uncertainty in the calculation of the GIC sea-level contribution. It also allows for a comparison of the recent inventory to earlier results (Sect. 4.2.1).

In Fig. 1 it can be seen that the division of glacier area over the regions is similar for both inventories. However, as the volume-area relation is non-linear, the volume also depends on the size distribution of the glaciers in each region and thus the volume will not necessarily be equal for both data sets. These differences in the initial volume in $1990\left(V_{\mathrm{i}}\right)$ are a potential source of uncertainty and will be addressed in Sect. 4.
Table 2. CMIP3-Models used in this study.

\begin{tabular}{ll}
\hline Model name & Reference \\
\hline BCCR-BCM2.0 & Furevik et al. (2003) \\
CGCM3.1(T47) & Flato (2005) \\
ECHAM5/MPI-OM & Jungclaus et al. (2006) \\
GFDL-CM2.0 & Delworth et al. (2006) \\
GFDL-CM2.1 & Delworth et al. (2006) \\
GISS-EH & Schmidt et al. (2006) \\
GISS-ER & Schmidt et al. (2006) \\
GISS-AOM & Lucarini and Russell (2002) \\
MRI-CGCM2.3.2 & Yukimoto and Noda (2002) \\
MIROC3.2(hires) & K-1 model developers (2004) \\
NCAR-PCM & Washington et al. (2000) \\
UKMO-HadCM3 & Gordon et al. (2000) \\
\hline
\end{tabular}

\subsection{Twelve climate models}

The glacier model requires information on atmospheric temperature and precipitation to calculate the glacier contribution to sea-level change. These values are taken from the results of simulations with AOGCMs, of which the names and references are presented in Table 2. These models are a subset of the World Climate Research Programme's CMIP3 multi-model data set (Meehl et al., 2007a) used for IPCC AR4. This subset contains 12 models and was also used by Slangen et al. (2011). In this study we mainly consider the emission scenario A1B, as defined in the IPCC Special Report on Emission Scenarios (Nakićenović and Swart, 2000). In Sect. 4.4, the uncertainty resulting from the choice of emission scenario will be discussed, by using scenarios B1 and A2. The ensemble mean global average temperature increase in $2090-2099$ w.r.t. $1980-1999$ is $+2.8^{\circ} \mathrm{C}(1.7$ to $\left.4.4^{\circ} \mathrm{C}\right)$ for the A1B scenario, $+1.8^{\circ} \mathrm{C}\left(1.1\right.$ to $\left.2.9^{\circ} \mathrm{C}\right)$ for $\mathrm{B} 1$, and $+3.4^{\circ} \mathrm{C}\left(2.0\right.$ to $\left.5.4^{\circ} \mathrm{C}\right)$ for $\mathrm{A} 2$ (Meehl et al., 2007b).

As the resolution of the different climate models is highly variable, the data are bilinearly interpolated to one grid to be able to construct an ensemble mean. We choose a grid with 512 longitude points and 256 latitude points, as this is the grid used in the sea-level model that calculates the sea-level patterns resulting from land ice mass changes.

In order to apply the ensemble mean climate forcing to the two glacier inventories R10 and W01 we use temperature and precipitation differences between 1980-2000 and 20902099. The values at each of the 135 locations of the W01 data set are averaged over the 14 regions as defined in Table 1. These mean values are used as forcing for the volume-area model. This procedure is necessary as the locations of the upscaled GIC in R10 are only known by region. 


\section{Reference experiment and past sea-level contribution}

\subsection{Reference experiment}

A reference experiment is defined for the remainder of this study, using the R10 glacier inventory. The reference $V_{\mathrm{i}}$ in 1990 is calculated using Eq. (1), with $c=0.2055 \mathrm{~m}^{3-2 \gamma}$ and $\gamma=1.375$, which are the values proposed by R10. This results in a $V_{\mathrm{i}}$ of $1.8122 \times 10^{14} \mathrm{~m}^{3}$, or $0.50 \mathrm{~m} \mathrm{SLE}$. Note that ice caps are included using $c=1.7026 \mathrm{~m}^{3-2 \gamma}$ and $\gamma=1.25$. These ice cap values are kept constant throughout this study, and variations on model parameters will only be performed on the glacier part, which is the largest contribution: $89 \%$ glacier area vs. $11 \%$ ice cap area. The value of $0.50 \mathrm{~m} \mathrm{SLE}$ is lower than the original value by R10 ( $0.60 \mathrm{~m} \mathrm{SLE})$, because glaciers around Antarctica are excluded as they are not explicitly located in R10 and only taken into account by a scaling consideration in W01. Using the settings as described in Sect. 2.1, we compute a sea-level contribution for 1990-2090 $(\delta V)$ of $0.149 \pm 0.022 \mathrm{~m} \mathrm{SLE}$ for the reference experiment.

To compare the results for the two glacier inventories, the total $V_{\mathrm{i}}$ of the W01 inventory is tuned such that it equals the total $V_{\mathrm{i}}$ of the reference experiment R10, by varying the scaling factor $c$ in Eq. (1). The value found for W01 is $c=0.144 \mathrm{~m}^{3-2 \gamma}$. This value for $c$ is slightly larger than the original value adopted by $\mathrm{W} 01$ of $0.12 \mathrm{~m}^{3-2 \gamma}$, which would yield a $V_{\mathrm{i}}$ of $0.42 \mathrm{~m} \mathrm{SLE}$ for all glaciers except the Antarctic region, and $0.5 \mathrm{~m} \mathrm{SLE}$ including glaciers around Antarctica and Greenland. With a $c$ of $0.144 \mathrm{~m}^{3-2 \gamma}$ and all other settings as in the reference experiment, we find for the W01 glacier inventory a $\delta V$ of $0.176 \pm 0.025 \mathrm{~m}$ SLE.

Using the two glacier inventories thus leads to a difference of $0.027 \mathrm{~m} \mathrm{SLE}$ in $\delta V$, which is quite large: $18 \%$ difference with respect to the R10 reference inventory. The reason for this difference will be analysed in Sect. 4.2.1.

\subsection{Past sea-level contribution}

The model is set up such that a steady state with the prevailing climate is assumed before 1865 , after which a temperature perturbation of $0.7^{\circ} \mathrm{C} 100 \mathrm{yr}^{-1}$ is applied for the period 1865-1990. By imposing this temperature perturbation it is ensured that GIC are not in a steady state in 1990, which is very important for future projections (Z97, Van de Wal and Wild, 2001). Other methods to account for the imbalance with climate are for instance by modelling the accumulation area ratio (e.g. Bahr et al., 2009) or the equilibrium-line altitude (e.g. Raper and Braithwaite, 2006). The influence of the choice of temperature perturbation will be shown in Sect. 4.1.3.

For the reference experiment, the 1865-1990 GIC sealevel contribution is $0.057 \mathrm{~m}$ for the $\mathrm{R} 10$ data and $0.064 \mathrm{~m}$ for the W01 data. In Fig. 2 the modelled sea-level contributions of R10 and W01 (blue and red line, respectively) are compared to the pentadal mass balance series of Cogley (2009b)

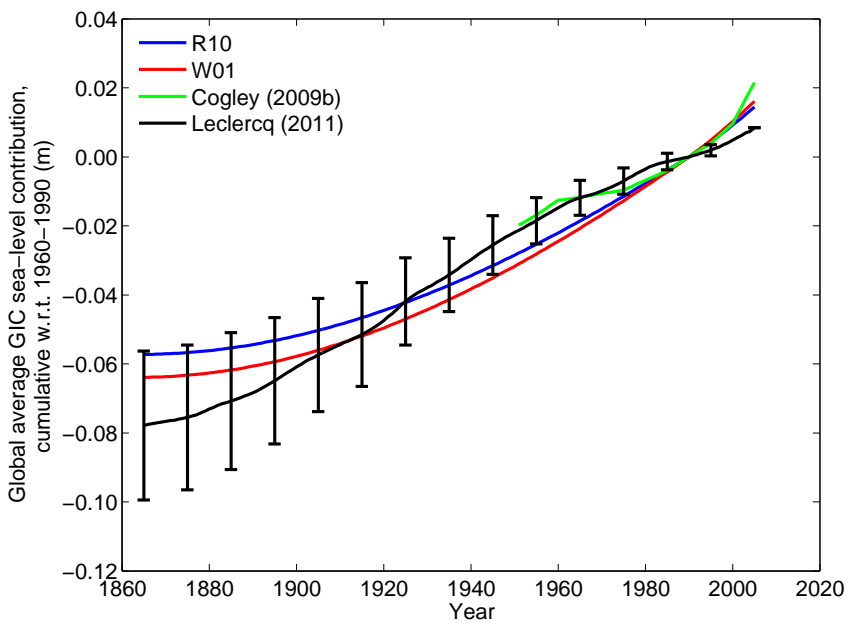

Fig. 2. Global average GIC sea-level contribution (m) relative to 1990.

(green line) and the estimated GIC contribution of Leclercq et al. (2011) (black line). The latter is a global reconstruction of glacier length records back to 1800 using volume-length scaling (Bahr et al., 1997; Oerlemans et al., 2007). Note that the total area differs between the data sets: Cogley (2009b) uses $785000 \mathrm{~km}^{2}$, Leclercq et al. (2011) use $704000 \mathrm{~km}^{2}$ (both include Antarctic glaciers), W01 has a surface area of $597613 \mathrm{~km}^{2}$ and R10 is the smallest with $568709 \mathrm{~km}^{2}$ (both R10 and W01 exclude Antarctic glaciers).

The data of Cogley (2009b) are available from 1950 onwards. In Fig. 2 the Cogley data shows pentadal variability, which is not present in W01 and R10 because a uniform temperature increase was applied. The model results are also compared to the values of Leclercq et al. (2011), who find a contribution of $0.078 \pm 0.022 \mathrm{~m}$ for the period $1865-1990$. R10 and W01 show a smaller increase for the 1865-1925 period than Leclercq et al. (2011), which is probably caused by a different history before 1865 . The volume-area model assumes all glaciers to be in balance with climate before 1865 , whereas the Leclercq et al. data are already in imbalance in 1865 (Leclercq et al., 2011, their Fig. 6). Nevertheless, the period after 1925 shows a cumulative sea-level contribution similar to our experiments, which indicates that applying the imbalance of $0.7^{\circ} \mathrm{C} 100 \mathrm{yr}^{-1}$ for the $1865-1990$ period is appropriate when calculating the contribution from 1990-2090.

\section{Sensitivity experiments}

A set of sensitivity experiments is described in this section. First, the model set-up is investigated, by varying some of the model parameters. The three experiments that will be discussed are the mass balance sensitivity (Sect. 4.1.1), the scaling factor $c$ in Eq. (1) (Sect. 4.1.2) and the imbalance histories (Sect. 4.1.3). Next, the input of the model, i.e. the glacier data, is discussed in Sect. 4.2. Finally, the twelve climate 


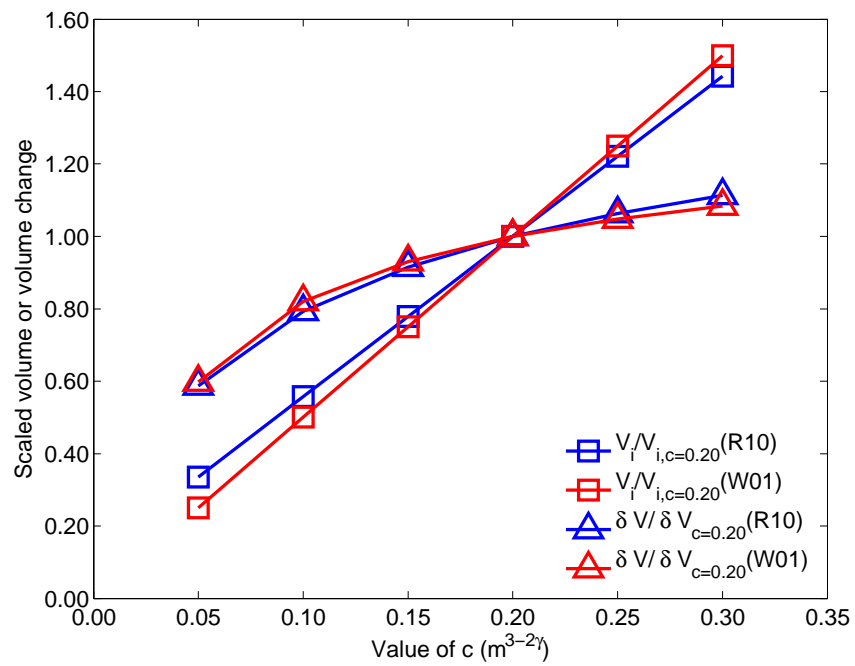

Fig. 3. Initial GIC volume $\left(V_{\mathrm{i}}\right)$ relative to $V_{\mathrm{i}, c=0.20}$, and 1990-2090 GIC sea-level contribution $(\delta V)$ relative to $\delta V_{c=0.20}$.

models (Sect. 4.3) and the influence of different emission scenarios are discussed (Sect. 4.4).

\subsection{Glaciological analytical uncertainty}

\subsubsection{Mass balance sensitivity}

The mass balance sensitivity of a glacier indicates how the mass balance responds to changes in temperature and precipitation. Oerlemans and Fortuin (1992) found that it strongly depends on the amount of precipitation the glacier receives in a year. We therefore use Eqs. (3) and (4) to relate mass balance sensitivity to precipitation, as proposed by Z97. The mass balance sensitivity relation is a parameterisation based on mass balance observations on 12 glaciers described in Oerlemans and Fortuin (1992) and Oerlemans (1994), which has been confirmed by Braithwaite and Raper (2002). However, the mass balance sensitivity may vary between different climate zones, and those 12 glaciers possibly are not representative for the entire distribution of GIC on Earth. Hence, we study the effect of the uncertainty in the mass balance sensitivity.

To test the consequences of variations in the mass balance sensitivity, we apply a variation of $\pm 20 \%$, which is considered a fair estimate of the uncertainty due to the limited data set used to derive the sensitivity. Additionally, the precipitation used to calculate the mass balance sensitivity is varied by $\pm 20 \%$.

Varying the total mass balance sensitivity by $\pm 20 \%$ leads to a deviation of $17 \%$ in the future sea-level contribution. Varying the precipitation rate by $\pm 20 \%$ leads to smaller changes in $\delta V$ of $12 \%$, since variations in precipitation rate are related to variations in mass balance sensitivity through Eqs. (3) and (4). Thus, differences in precipitation rate are less important than variations in the mass balance sensitivity itself given a range of variation of $20 \%$. With respect to the reference experiment, varying the mass balance sensitivity by $\pm 20 \%$ leads to a deviation of $0.026 \mathrm{~m} \mathrm{SLE}$ in the projected sea-level change.

\subsubsection{Scaling factor $c$}

In this second sensitivity experiment, the scaling factor $c$ in Eq. (1) is varied by a range of 0.05 to $0.30 \mathrm{~m}^{3-2 \gamma}$. This influences not only the 1990-2090 contribution of GIC to sealevel change $(\delta V)$, but also the initial volume in $1990\left(V_{\mathrm{i}}\right)$, because both are calculated by applying the volume-area relation (Eq. 1) to the glacier data.

The results in terms of $V_{\mathrm{i}}$ and $\delta V$ for variations in the scaling factor $c$ are shown in Fig. 3. In this figure, the values obtained for $V_{\mathrm{i}}$ and $\delta V$ with $c=0.20 \mathrm{~m}^{3-2 \gamma}$ are taken as reference values, and the quantities shown are $V_{\mathrm{i}}$ and $\delta V$ relative to these reference values for a range of values of $c: \frac{V_{\mathrm{i}}}{V_{\mathrm{i}, c=0.20}}$ and $\frac{\delta V}{\delta V_{c=0.20}}$. Figure 3 shows that the scaled $V_{\mathrm{i}}$ increases linearly with $c$, for both the R01 and the W01 glacier inventory. However, the scaled $\delta V$ shows a different, less sensitive, response than the scaled $V_{\mathrm{i}}$ to an increase in $c$. If values for $c$ are varied by $\pm 0.05 \mathrm{~m}^{3-2 \gamma}(25 \%), V_{\mathrm{i}}$ changes by $25 \%$, while $\delta V$ varies by only $9 \%$ ( $0.014 \mathrm{~m} \mathrm{SLE})$. This means that small deviations in $c$ will not have a large influence on the modelled contribution of GIC to sea-level change. This is encouraging since $c$ is poorly constrained and may therefore vary between glaciers and regions, which is reflected by the different values that can be found in the literature (e.g. Bahr, 1997; Chen and Ohmura, 1990).

The cause of the different response of $V_{\mathrm{i}}$ and $\delta V$ to variations in $c$ can be explained by the fact that GIC in a changing climate generally do not reach a new equilibrium state in $100 \mathrm{yr}$ time, except smaller glaciers, which may disappear completely. This is illustrated in Fig. 4, where the volume evolution in time for a few glacier size classes is shown. The figure also shows that the GIC in the larger size classes are still in the transition phase of adjusting to climate change. In the volume-area approach, GIC can only reach a new equilibrium by disappearing, unlike the methods of Raper and Braithwaite (2006) or Radić and Hock (2011), which can reach a new equilibrium over time. However, these methods require more information on the GICs hypsometry, which is not available for all glaciers. Additionally, larger glaciers will not reach an intermediate equilibrium within $100 \mathrm{yr}$, and therefore the volume-area method provides sufficient results for this period.

Figure 4 suggests that the volume evolution in time can be described by an arccotan function. This is the case for all glacier size classes separately, but also for the total GIC volume. Hence, the evolution of volume with time $\left(t, t_{0}=1865\right)$ can be written as:

$V^{*}=\frac{\pi}{2}+\operatorname{arccotan} \frac{t-D}{E}$, 

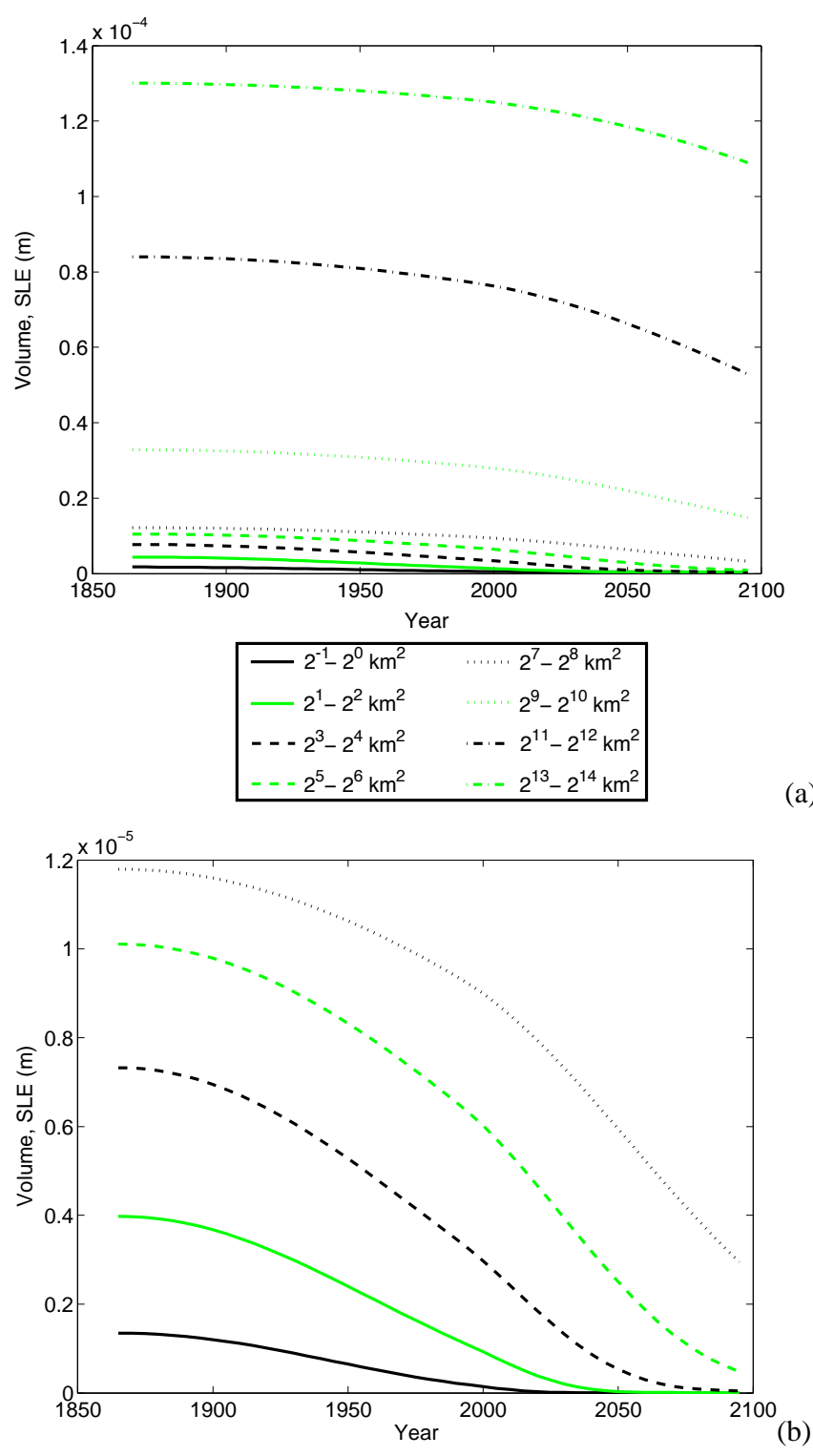

Fig. 4. Volume evolution (m) in time for (a) every second size class for reference experiment R10 and (b) close-up of the smallest 5 size classes in (a).

where $V^{*}$ is $\frac{V_{t}}{V_{0}}, D$ is the year where $V_{t}$ is 0 , and $E$ is a mathematical constant describing the fit without any specific physical interpretation. Equation (5) is only valid for $t<D$. As an example, fits have been made for the R10 data set of the total modelled GIC volume for 1865-2090, for different values of $c$. The parameters resulting from the fits are shown in Table 3. From the Table it appears that, while $D$ and $E$ both increase for larger $V_{\mathrm{i}}, D / E$ is more or less constant. The derivative of Eq. (5) reads:

$\frac{\delta V^{*}}{\delta t}=\frac{1}{1+t_{*}^{2}}$
Table 3. Results of fits on the evolution of $V$ (Eq. 5) for 3 values of $c$ (Eq. 1), using the R10 data. $V_{t=0 \mathrm{yr}}$ represents the 1865 volume, $V_{t=125 \mathrm{yr}}$ the 1990 volume, $V_{t=225 \mathrm{yr}}$ the 2090 volume, $D$ and $E$ are fitted constants in yr. Sea-level equivalent (SLE) is calculated assuming an ocean area of $3.62 \times 10^{8} \mathrm{~km}^{2}$.

\begin{tabular}{lccc}
\hline & $\begin{array}{c}\text { Small } V_{\mathrm{i}} \\
c=0.1\end{array}$ & $\begin{array}{c}\text { Medium } V_{\mathrm{i}} \\
c=0.15\end{array}$ & $\begin{array}{c}\text { Large } V_{\mathrm{i}} \\
c=0.2\end{array}$ \\
\hline$V_{t=0 \mathrm{yr}}(\mathrm{SLE} \mathrm{m})$ & 0.33 & 0.44 & 0.54 \\
$V_{t=0 \mathrm{yr}}\left(10^{5} \mathrm{~km}^{3}\right)$ & 1.22 & 1.58 & 1.97 \\
$V_{t=125 \mathrm{yr}}\left(10^{5} \mathrm{~km}^{3}\right)$ & 0.99 & 1.39 & 1.78 \\
$V_{t=225 \mathrm{yr}}\left(10^{5} \mathrm{~km}^{3}\right)$ & 0.61 & 0.95 & 1.30 \\
$D(\mathrm{yr})$ & 338 & 402 & 454 \\
$E(\mathrm{yr})$ & 204 & 240 & 270 \\
$D / E$ & 1.66 & 1.68 & 1.68 \\
Volume loss $\left(10^{5} \mathrm{~km}^{3}\right)$ & 0.38 & 0.44 & 0.48 \\
\hline
\end{tabular}

with $t_{*}$ being $(t-D) / E$. As $E$ ranges from 200 to 270 , this implies that for the first $200 \mathrm{yr}$ differences in the volume loss over time are small. We indeed see that when $c$ is varied by $\pm 25 \%$, the $\delta V^{*}$ between 125 and 225 yr varies by only $10 \%$. As a consequence, the exact value of $c$ is not that important within the time frame considered.

We have performed a similar sensitivity study on the other parameter in Eq. (1), $\gamma$. Available estimates for $\gamma$ are 1.375 (Bahr, 1997), used in this study, and 1.36 (Bahr et al., 1997). The range over which $\gamma$ is tested is based on the difference between the two estimates: 1.345 to 1.405 with steps of 0.015 . From this we also find that $V_{\mathrm{i}}$ is more sensitive to the choice of the scaling exponent $\gamma$ than $\delta V$, which is fairly insensitive to variations in $\gamma$.

\subsubsection{Imbalance in 1990}

Throughout this study, the 1990 imbalance of the GIC is simulated by imposing a temperature change of $0.7^{\circ} \mathrm{C} 100 \mathrm{yr}^{-1}$ for the period 1865-1990, which is in line with the IPCC AR4 estimate (see Table 3.2 in Trenberth et al., 2007). However, in this section we will impose a range of different options for the imbalance on the R10 data to quantify their influence on the future sea-level change.

The first option we explore is to calculate the GIC contribution without an imbalance. This means that the glacier model starts its calculations in 1990, which clearly influences the resulting contribution (Fig. 5, light blue line) with a difference as large as $39 \%$ from the reference experiment $\left(0.7^{\circ} \mathrm{C} 100 \mathrm{yr}^{-1}\right.$, black line $)$. However, it is not very realistic to assume that GIC are currently in balance with climate, and this option shows how important it is to include an imbalance, as it has a large influence on the future sea-level contribution (compare e.g. Z97).

As a second test, the rate of temperature change for 18651990 is varied: $0.6^{\circ} \mathrm{C} 100 \mathrm{yr}^{-1}$ (Fig. 5, magenta line) and 


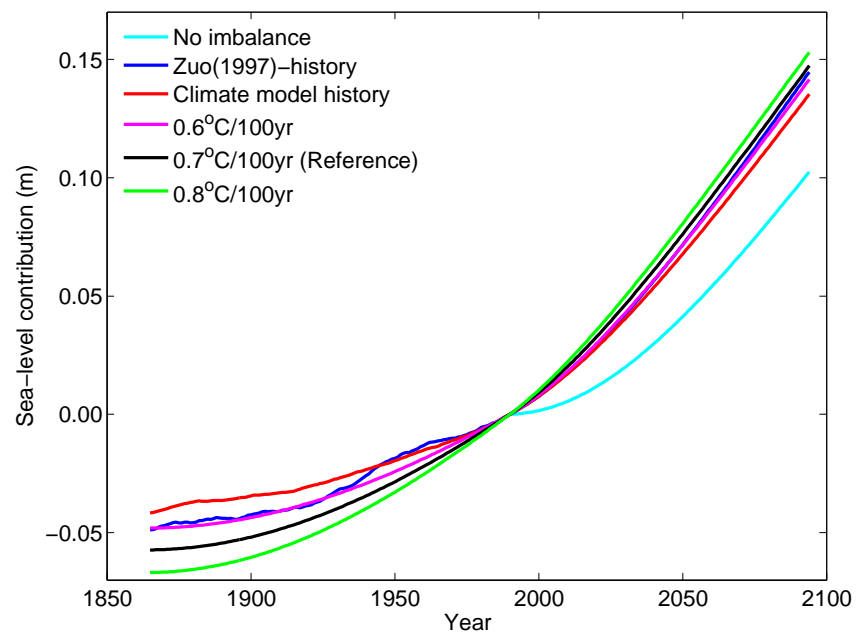

Fig. 5. GIC sea-level contribution (m) for different imbalance options, R10 glacier inventory.

$0.8^{\circ} \mathrm{C} 100 \mathrm{yr}^{-1}$ (green line). For the sea-level contribution before 1990 this results in deviations of about $\pm 0.01 \mathrm{~m}$ from the reference in 1865. However, for the future sea-level contribution the differences are in the order of $\pm 0.005 \mathrm{~m}$, which is about $4 \%$. This indicates that the exact value of the rate of temperature change is not a large source of uncertainty for the future contribution, as long as the value chosen is close to the observations.

Another factor that influences the volume change is the precipitation. Increasing the initial precipitation rate in 1990 leads to a larger contribution from the GIC to sea-level change, because the mass-balance sensitivity highly depends on the precipitation rate and will consequently increase. This makes GIC more sensitive to temperature changes. We find that an increase of $10 \%$ in the precipitation rate in 1990 combined with a temperature change of $0.6^{\circ} \mathrm{C} 100 \mathrm{yr}^{-1}$ for the imbalance leads to a similar sea-level contribution by 2090 as a temperature increase of $0.7^{\circ} \mathrm{C} 100 \mathrm{yr}^{-1}$. The same holds for a temperature change of $0.8^{\circ} \mathrm{C} 100 \mathrm{yr}^{-1}$ combined with a precipitation decrease of $10 \%$.

To test the influence of regional variations, we now prescribe a temperature change for each region separately, similar to the way the modeled climate changes are used for the 1990-2090 period (see Sect. 2.3). We test two options: for the first we use a compilation of historical temperatures from Z97 (Fig. 5, dark blue line); for the second we take the regional temperatures from the 20th century climate model runs (20C3M, Fig. 5, red line). Figure 5 shows that for the 1990-2090 contribution the Z97 data are very close to the $0.7^{\circ} \mathrm{C} 100 \mathrm{yr}^{-1}$ option and the $20 \mathrm{C} 3 \mathrm{M}$ data result in a slightly smaller contribution. For the 1865-1990 contribution, the difference is larger, $0.01 \mathrm{~m}$ for Z97 and $0.02 \mathrm{~m}$ for the climate models. This indicates that taking regional values for the temperature change over the past, despite having in-

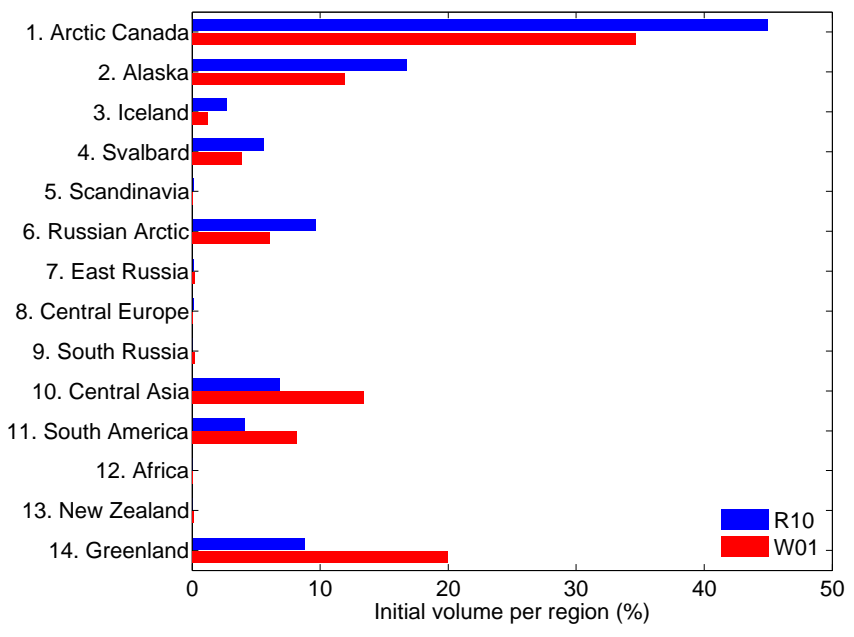

Fig. 6. Initial GIC volume per region relative to $V_{\mathrm{i}}$ for the two inventories $\left(V_{\mathrm{i}, \mathrm{R} 10}=V_{\mathrm{i}, \mathrm{W} 01}\right)$.

fluence on the past contribution, does not have a large impact on the future contribution.

As can be seen in Fig. 5, the different options for the imbalance show larger deviations in the past volume change than in the future contribution. The past contribution acts as a spin-up period, and starts with all glaciers in balance with climate. Depending on the prescribed climate, the glaciers are brought in imbalance with climate, leading to relatively large deviations from the reference run. For the future contribution however, the climate is taken from the AOGCMs, so the only difference is the initial imbalance in 1990. It appears that this leads to differences in the past being more pronounced than in the future contribution.

Summarising, we find that if an imbalance is included (all options except "no imbalance"), the average deviation in the future contribution is $0.009 \mathrm{mSLE}$, provided that the temperature increase between 1865 and 1990 is around $0.7^{\circ} \mathrm{C} 100 \mathrm{yr}^{-1}$.

\subsection{Glaciological data uncertainty}

\subsubsection{Choice of inventory}

In this section we consider the importance of the geometrical input to the model and its influence on the resulting GIC sea-level contribution $(\delta V)$. We compare the two glacier inventories using the reference experiment settings as defined in Sect. 3.1. As mentioned before, the initial area per region (Fig. 1) is quite similar for both glacier inventories. Furthermore, since the experiment considered here is the reference experiment, also $V_{\mathrm{i}}$ is similar. However, $V_{\mathrm{i}}$ is not divided equally over the different regions. In Fig. 6 it can be seen that there are substantial differences between the two inventories. In Central Asia, South America and Greenland the 

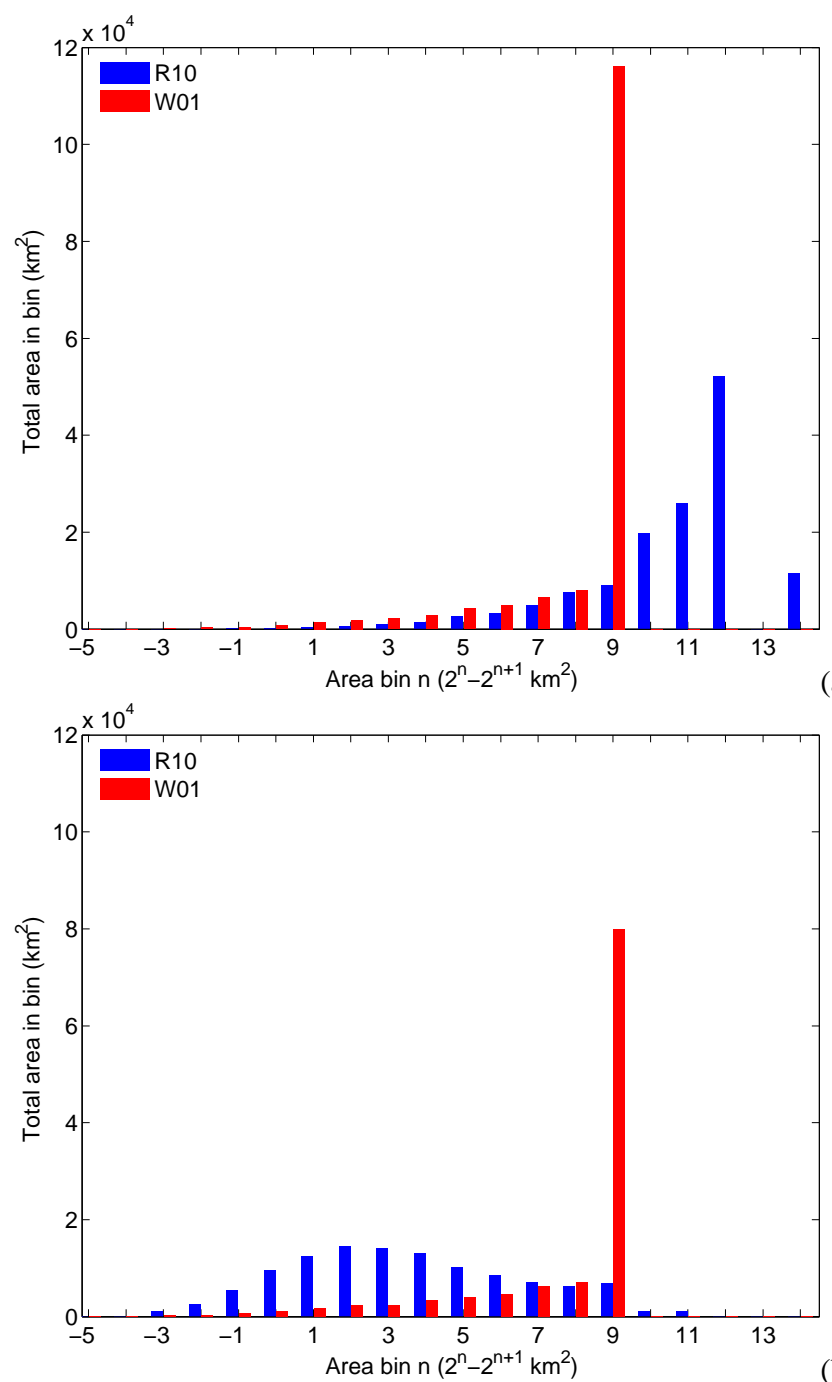

(b)

Fig. 7. Initial (1990) GIC area $\left(\mathrm{km}^{2}\right)$ per size bin for (a) Arctic Canada and (b) Central Asia. R10 uses size bins -3 (all GIC with area $\left.<2^{-2} \mathrm{~km}^{2}\right)$ to $14\left(>2^{14} \mathrm{~km}^{2}\right)$, W01 uses size bins $-5(<$ $\left.2^{-4} \mathrm{~km}^{2}\right)$ to $9\left(>2^{9} \mathrm{~km}^{2}\right)$.

regional $V_{\mathrm{i}}$ in $\mathrm{R} 10$ is smaller than the $V_{\mathrm{i}}$ in W01, while the opposite is true for Canada, Alaska and the Russian Arctic.

To explain the cause of these differences, we focus on Arctic Canada and Central Asia. Arctic Canada occupies $25 \%$ of the initial area in both data sets, but the $V_{\mathrm{i}}$ differs substantially ( $10 \%$ more in R10). Figure 7 a shows how the total area is divided over the size bins: the largest W01 size bin $\left(>2^{9} \mathrm{~km}^{2}\right)$ contains most of the W01 area, where the R10 size bins (until $>2^{14} \mathrm{~km}^{2}$ ) allow for a more precise classification of these larger GIC. To calculate the volume of the GIC, the average area in the size bins is used. In the volumearea relation, volume increases with the 1.375 power of the area, which means that the larger size bins of R10 result in a larger volume, explaining the different $V_{\mathrm{i}}$ for this region. As a second example, the size bins for Central Asia are shown in

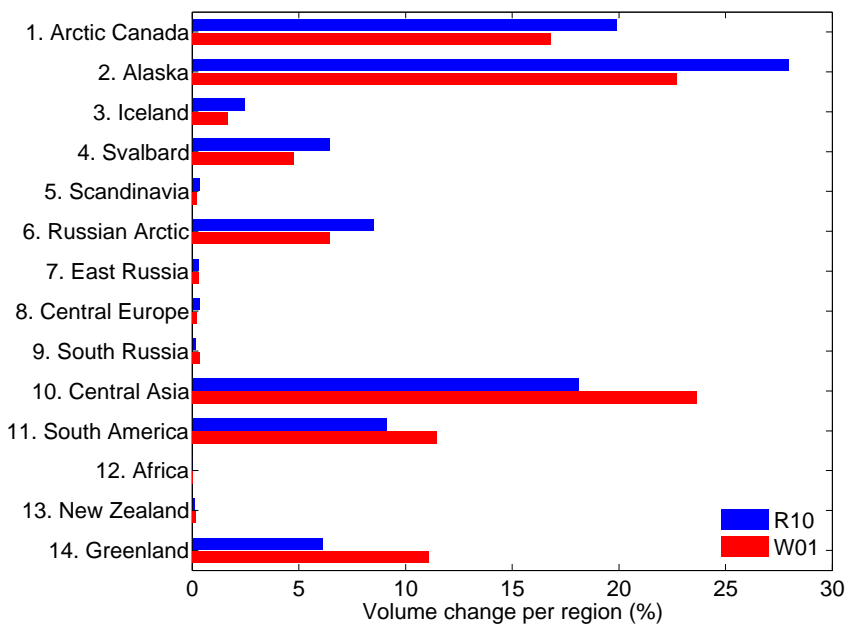

Fig. 8. GIC sea-level contribution per region relative to total $\delta V$.

Fig. 7b. In this case, W01 classifies more GIC into the largest size bin than R10, which leads to a higher $V_{\mathrm{i}}$ for the W01 data. Hence, differences in $V_{\mathrm{i}}$ per region are often caused by differences in the classification of GIC in size bins. These classification differences are not only the result of the increased number of glaciers in the R10 data set, but also due to the division of large ice bodies into smaller glaciers.

The R10 reference experiment yields a $\delta V$ of 0.149 $\pm 0.022 \mathrm{mSLE}$, while using W01 results in $0.176 \pm$ $0.025 \mathrm{~m}$ SLE, which is a difference of $0.027 \mathrm{~m}$ SLE. The uncertainty represents one $\sigma$ uncertainty among the 12 climate models, and will be further discussed in Sect. 4.3. Figure 8 shows the ensemble mean $\delta V$ per region relative to $V_{\mathrm{i}}$ for both glacier inventories. The larger differences $(>1 \%)$ between the two inventories are in regions with significant contributions; Arctic Canada, Alaska, Svalbard, the Russian Arctic, Central Asia, South America and Greenland. So, although the $V_{\mathrm{i}}$ is the same, the regional contributions of $V_{\mathrm{i}}$ and $\delta V$ differ significantly. This is important when local sealevel change is the key interest rather than the global average sea-level change.

The relative values in Figs. 6 and 8 show how the mass change is divided over the regions, but not how this relates to the $V_{\mathrm{i}}$ per region. Therefore, $V_{\mathrm{i}}$ and the GIC volume change are presented in $\mathrm{m}$ SLE per region in Fig. 9. This immediately shows the largest glaciated regions and the regions with the highest mass loss. The $V_{\mathrm{i}}$ of R10 is clearly larger in Arctic Canada, Alaska, Iceland, Svalbard and the Russian Arctic, while W01 shows larger values in Central Asia, South America and Greenland. The total $\delta V$ is larger for the W01 data, which is mainly caused by differences in Central Asia, South America and Greenland. This can again be explained by the way GIC are classified into size classes in the two inventories.

For each of the two data sets, the sea-level change pattern resulting from the ice mass changes is computed with 


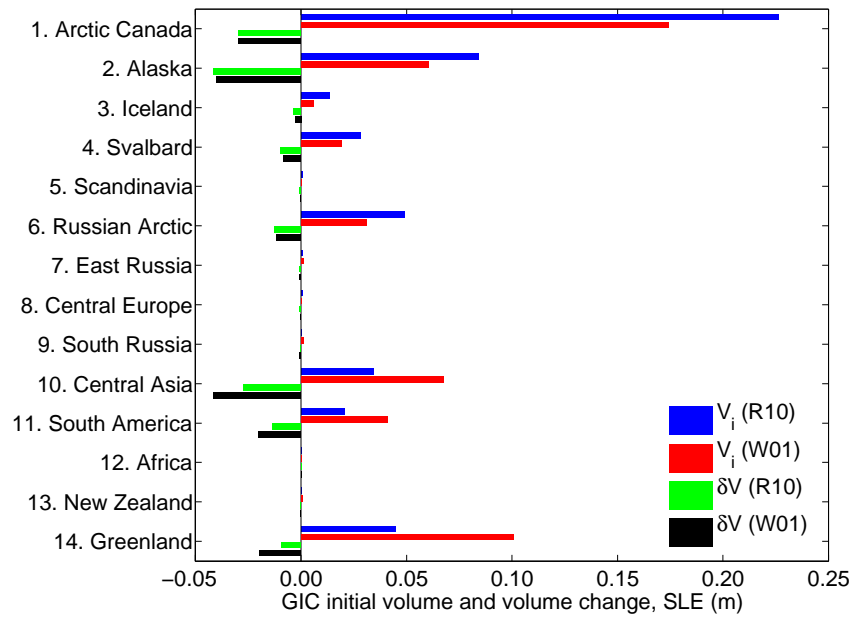

Fig. 9. GIC initial volume $\left(V_{\mathrm{i}}\right)$ and volume change per region $(\delta V)$, SLE (m).

a sea-level model (Schotman, 2008). This model calculates a gravitationally consistent field of sea-level change while accounting for rotational processes. For more information on the model, the reader is referred to Slangen et al. (2011). The model results are shown in Fig. 10a, where the percentage presented is $\frac{\delta V_{\text {local }}}{\delta V_{\text {global mean }}} \cdot 100 \%$, which is the local sealevel change due to GIC relative to the global mean sea-level change due to GIC. In the figure, values below zero imply a sea-level drop, values between 0 and $100 \%$ imply a sea-level rise below the R10 global average, and values above $100 \%$ indicate a sea-level rise larger than the global average. Figure 10a shows that, except for Patagonia, the Southern Hemisphere will experience a sea-level rise greater than average, the Northern Hemisphere a rise less than average and parts of the Arctic region will even experience a sea-level drop from the contribution of GIC. This is because most glaciers are situated around the Arctic, where the largest decrease in ice mass will be and thus the largest changes in the graviational field. Differences further inland, such as in Central Asia, only have a minor effect.

In Fig. 10b the differences in the sea-level change pattern between R10 and W01 are shown in percentages. A positive value indicates that $\mathrm{R} 10$ has a larger relative sea-level change, while a negative value implies a larger relative sealevel change for W01. Regions with substantial differences between the two inventories are Patagonia and the high Arctic, where the largest differences in sea-level pattern can be found close to the largest melt sources. This is a consequence of the non-linear pattern of the gravitational adjustment with a strong response close to the source of mass change and a gradual transition in the far field. Consequently, further away from the melting ice the patterns of R10 and W01 are very similar.
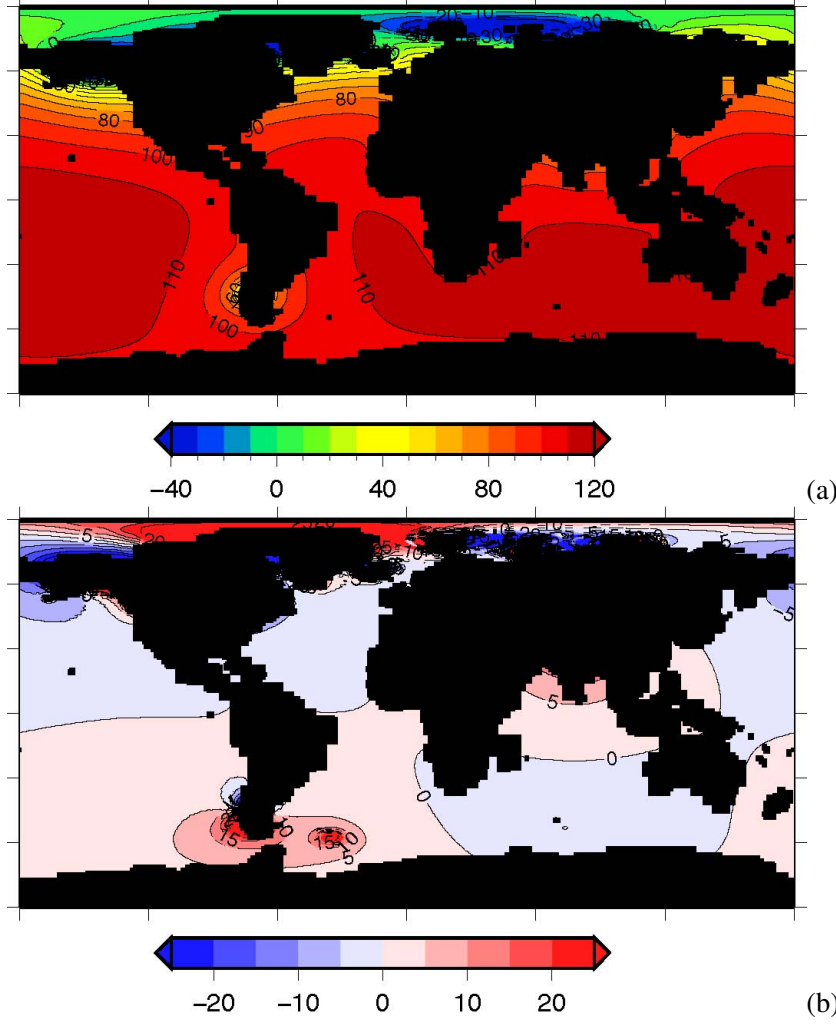

(b)

Fig. 10. (a) Local sea-level change (1990-2090) relative to the ensemble global mean sea-level change (\%) (R10, global average $0.149 \mathrm{~m})$. (b) Difference in relative sea-level change (\%) (R10W01).

\subsubsection{Data uncertainty}

While in the previous section two inventories were compared, this section will consider the measurement uncertainties of each of the glacier inventories. These uncertainties are for instance due to the data being obtained from various sources, or not all regions being complete. To show how this influences the GIC sea-level contribution, we vary the initial GIC area by an arbitrarily chosen $\pm 10 \%$. For R 10 , this results in variations in the GIC contribution of $\pm 0.017 \mathrm{~m}$, while for W01 it is $\pm 0.019 \mathrm{~m}$. This is a deviation of $11 \%$ with respect to the reference value, which is substantial. This shows that it is of great importance that the glacier inventories are completed with the highest possible accuracy.

\subsection{Climate model uncertainty}

The ensemble mean sea-level change (1990-2090) calculated for the reference experiment is $0.149 \pm 0.022 \mathrm{~m} \mathrm{SLE}$ for $\mathrm{R} 10$ and $0.176 \pm 0.025 \mathrm{~m}$ SLE for W01. These uncertainties are based on the spread in the climate models used for the calculations (Sect. 2.3). In this section we consider the $\delta V$ for the twelve climate models individually. In Fig. 11, $\delta V$ is shown for each climate model and both glacier inventories 


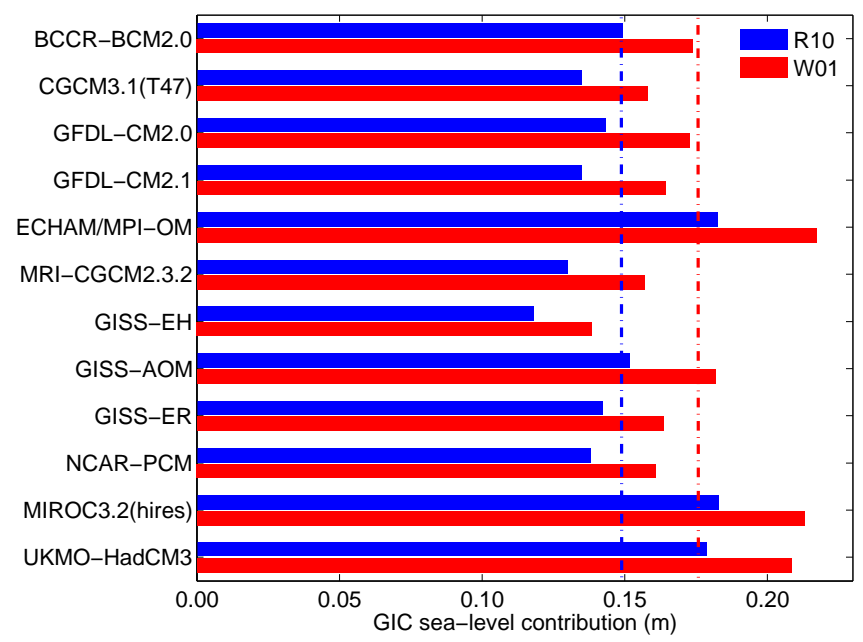

Fig. 11. GIC sea-level contribution ( $\mathrm{m}$ ) for the 12 climate models and the two glacier inventories (1990-2090). Dashed lines represent model mean contribution for each inventory.

separately. The dashed line indicates the ensemble mean value of each inventory. The figure shows that there are large differences among the climate models, yielding GIC contributions in the range of 0.12 to $0.22 \mathrm{~m}$ SLE. These differences are caused by variations in temperature and precipitation patterns of the climate models. All models consistently present larger contributions for the W01 data set than for R10, due to differences in the classification of the GIC in size bins. The difference between the highest and the lowest climate model is $0.065 \mathrm{~m}$ (R10) and $0.079 \mathrm{~m}$ (W01), the largest absolute deviation from the ensemble mean is $0.034 \mathrm{~m}$ (R10) and $0.042 \mathrm{~m}$ (W01). The average absolute deviation from the ensemble mean for both data sets combined is $0.018 \mathrm{~m}$ or $12 \%$. Clearly, the choice of climate model has a significant impact on the resulting GIC contribution. It is therefore important to use a large ensemble and not to rely on a single climate model as long as we cannot prove one to be superior to the others.

\subsection{Emission scenario uncertainty}

Closely connected to the choice of climate model is the emission scenario that is chosen to drive the climate model. Throughout this study, the A1B scenario has been used. However, depending on the socio-economic developments in the next century, the actual emissions might be higher or lower than in the A1B scenario, which will of course influence the temperature change and the amount of GIC melt and thus the sea-level contribution. Therefore, we also show the GIC sea-level contribution resulting from calculations with the A2 and B1 scenarios (Nakićenović and Swart, 2000). The A2 and B1 model ensembles are slightly smaller than the A1B scenario, as not all AOGCMs are available for these scenarios. In the A2 ensemble, GISS-EH and GISS-
$\mathrm{AOM}$ are not available, leading to a ensemble size of 10 models. For B1, GISS-EH is not available, thus leading to an ensemble size of 11 models. The resulting GIC contribution to sea-level change, using the R10 inventory, is $0.168 \pm 0.021 \mathrm{~m} \mathrm{SLE}$ for A2 and $0.128 \pm 0.018 \mathrm{~m} \mathrm{SLE}$ for $\mathrm{B} 1$. It is not surprising that the warmer A2 scenario yields a higher GIC contribution than the cooler B1 scenario. These results show that the choice of emission scenario is an important factor, as the deviation from the A1B scenario is on average $0.020 \mathrm{~m} \mathrm{SLE}$ or $13 \%$.

\section{Conclusions}

This study examined sources of uncertainty in the computation of the future sea-level contribution of melting GIC with a volume-area model. Four sources of uncertainty were examined in Sect. 4, being the analytical uncertainty (Sect. 4.1), the data uncertainty (Sect. 4.2), the choice of climate model (Sect. 4.3), and the choice of emission scenario (Sect. 4.4). The results of the sensitivity studies are summarised in Table 4 , which shows the applied variations and the resulting ensemble mean deviations from the reference experiment for $\delta V$.

In Sect. 4.1.1, the mass balance sensitivity was varied by $\pm 20 \%$, which led to a variation of $\pm 17 \%$ or $0.026 \mathrm{~m} \mathrm{SLE} \mathrm{in}$ the GIC contribution to sea-level change. Thus, variations in mass balance sensitivity have a notable effect on the GIC sealevel contribution. This means that if the applied sensitivity is not representative for a global approach, it will introduce a significant error in the calculated sea-level contribution.

The influence of changes in scaling factor $c$ was examined in Sect. 4.1.2. It appeared that small variations in $c$ cause significant variations in the $V_{\mathrm{i}}$ in 1990 (25\%), but only limited changes in the future contribution to sea-level change. For a range of $\pm 0.05 \mathrm{~m}^{3-2 \gamma}, \delta V$ varied by only $\pm 9 \%$ or $0.014 \mathrm{~m}$. The remarkable difference in sensitivity between $V_{\mathrm{i}}$ and $\delta V$ can be explained by considering the time scale of interest (100 yr) and the response time of a glacier to a changing climate.

As glaciers are currently not in balance with climate, a temperature history has to be prescribed, for which several options were explored in Sect. 4.1.3. It appeared that it is important to include an imbalance, as excluding it leads to a systematic underestimation of the future sea-level contribution. The various options for a temperature history for the period 1865-1990 did not result in large deviations; the average difference is only $0.009 \mathrm{~m} \mathrm{SLE}$ for the future contribution.

If the two glacier inventories are tuned such that the $V_{\mathrm{i}}$ is the same, the $\delta V$ over $100 \mathrm{yr}$ differs by $0.027 \mathrm{~m}$. An important difference between the two data sets is the way the area is divided into size bins, which leads to differences in the contribution of some regions. As R10 has a more complete inventory in for instance Central Asia and Greenland, where differences between W01 and R10 are the largest, R10 
Table 4. Summary of the differences in $\delta V$ found with the sensitivity studies.

\begin{tabular}{lclcc}
\hline Sensitivity test & Section & Variation & Difference $(\mathrm{m})$ & Difference (\%) \\
\hline Mass balance sensitivity & 4.1 .1 & $\pm 20 \%$ & 0.026 & 17 \\
Scaling factor $c$ & 4.1 .2 & $\pm 25 \%$ & 0.014 & 9 \\
Imbalance in 1990 & 4.1 .3 & 5 options & 0.009 & 5 \\
Choice of inventory & 4.2 .1 & 2 datasets & 0.027 & 18 \\
Data uncertainty & 4.2 .2 & $\pm 10 \%$ & 0.017 & 11 \\
Choice of climate model & 4.3 & 12 models & 0.018 & 12 \\
Choice of emission scenario & 4.4 & 3 scenarios & 0.020 & 13 \\
\hline Total uncertainty & & & 0.052 & 35 \\
\hline No Imbalance & 4.1 .3 & no imbalance & 0.058 & 39 \\
\hline
\end{tabular}

probably gives a better indication of the GIC contribution than the older W01 data. The differences between these data sets indicate that it is very important to obtain information on the missing glaciers in the glacier inventories, especially in underrepresented but largely glaciated areas, such as Alaska, Arctic Canada and Antarctica.

Despite the differences in global mean values and among the different regions, we found that for the majority of the ocean surface there are only minor differences in the modelled sea-level change patterns between the two glacier inventories (Fig. 10b). The largest differences in the pattern occur close to the melt areas, such as in the Arctic region. Further away from the GIC, the sea-level change is above the global average due to the self-gravitation effect, and differences between results obtained with the two inventories are small.

Due to the partially incomplete inventories and the various data sources that contribute to the inventories, there is a measurement uncertainty. Section 4.2.2 showed that variations of $\pm 10 \%$ in the initial area lead to changes of $\pm 11 \%$ in the GIC contribution to sea-level change. This high sensitivity indicates that it is very important that the data in the inventories is as accurate as possible.

Section 4.3 showed that the choice of global climate model can lead to large differences in the GIC contribution. It is best to use an ensemble where possible, as this will reduce the influence of outliers in the climate models. Another way to reduce the uncertainty due to climate models would be to use AOGCMs with a smaller grid, such that smaller glacierised areas will be better represented in the climate model, because currently the grid size of the climate model is often larger than the size of the glacierised area (Randall et al., 2007). Additionally, glaciers are found in mountainous areas, which are poorly resolved by climate models. Therefore, the climate model yields a temperature and precipitation change that is possibly not representative for the glacierised area. Improving the climate models with an elevation-dependent correction will significantly reduce the uncertainty in calculating the GIC contributions and is therefore a crucial action for future work.
To simulate how the climate change depends on socioeconomic developments in the future, various emission scenarios have been developed (Nakićenović and Swart, 2000). In Sect. 4.4 a few of these scenarios were tested to determine the influence on calculations of the GIC contribution. It was found that the emission scenario uncertainty is of the same order as the climate model uncertainty.

An example of an uncertainty that could not be accounted for is the response of calving glaciers and tidewater glaciers to a warming climate. As indicated by Radić and Hock (2011) and references therein, the scarcity of estimates and complexity of the mechanisms do not allow for a good estimate of the contribution of these glaciers on a global scale. Therefore, the uncertainties presented here only concern the contribution to sea-level change as a response to surface mass balance changes.

Combining the uncertainties obtained with the sensitivity experiments in this study, we arrive at a total uncertainty of $0.052 \mathrm{~m}$ on a contribution of $0.149 \mathrm{~m}$ when using the volumearea approach, which is $35 \%$. The sea-level rise estimates of Meehl et al. (2007b), Meier et al. (2007), Pfeffer et al. (2008) and Radić and Hock (2011) mentioned in the introduction all fall at least partly within this range. The Meehl et al. (2007b) estimate is slightly lower than our contribution, which might be caused by our initial GIC volume estimate being higher than their highest volume estimate: $0.50 \mathrm{~m} \mathrm{SLE}$ vs. $0.37 \mathrm{~m}$ SLE. Radić and Hock (2011) use the same data set as in this study (R10), but find a lower contribution while they include Antarctica. They perform a different evaluation of the volume changes, because instead of grouping the glaciers into 14 regions, each glacier is modelled separately. Also, they use a volume-area-length approach instead of volume-area scaling. The difference between their result and this study is therefore also an illustration of the uncertainty due to differences of analytical method. However, the main uncertainties in their method are the same as those described in this study: a mass balance sensitivity based on few glaciers, an incomplete glacier database and the use of global climate models for temperature and precipitation. These points should therefore be the targets when 
aiming at improving the estimate of the GIC contribution to sea-level change.

Acknowledgements. We would like to thank P. Leclercq, R. Giesen, J. G. Cogley and an anonymous reviewer for their helpful comments and suggestions. We also thank NSIDC, WGMS, V. Radic and J. G. Cogley for collecting, archiving and providing the glacier inventories. We acknowledge the international modeling groups for providing their data for analysis, the Program for Climate Model Diagnosis and Intercomparison (PCMDI) for collecting and archiving the model data, the JSC/CLIVAR Working Group on Coupled Modelling (WGCM) and their Coupled Model Intercomparison Project (CMIP) and Climate Simulation Panel for organizing the model data analysis activity, and the IPCC WG1 TSU for technical support. A. S. is supported by the Netherlands Institute for Space Research (SRON) (ALW-GO-AO/07-14).

Edited by: I. M. Howat

\section{References}

Bahr, D. B.: Global distributions of glacier properties: A stochastic scaling paradigm, Water Resour. Res., 33, 1669-1679, doi:10.1029/97WR00824, 1997.

Bahr, D. B., Meier, M. F., and Peckham, S. D.: The physical basis of glacier volume-area scaling, J. Geophys. Res., 102, 2035520362, 1997.

Bahr, D. B., Dyurgerov, M., and Meier, M. F.: Sea-level rise from glaciers and ice caps: A lower bound, Geophys. Res. Lett., 36, L03501, doi:10.1029/2008GL036309, 2009.

Bindoff, N. L., Willebrand, J., Artale, V., Cazenave, A., Gregory, J., Gulev, S., Hanawa, K., Quéré, C. L., Levitus, S., Nojiri, Y., Shum, C. K., Talley, L. D., and Unnikrishnan, A. (Eds.): Observations: oceanic climate change and sea level, in: Climate Change 2007: The Physical Science Basis. Contribution of Working Group I to the Fourth Assessment Report of the Intergovernmental Panel on Climate Change, edited by: Solomon, S., Qin, D., Manning, M., Chen, Z., Marquis, M., Averyt, K. B., Tignor, M., and Miller, H. L., Cambridge University Press, Cambridge, UK and New York, NY, USA, 2007.

Braithwaite, R. J. and Raper, S. C. B.: Glaciers and their contribution to sea level change, Phys. Chem. Earth, 27, 1445-1454, 2002.

Chen, J. and Ohmura, A.: Estimation of Alpine glacier water resources and their change since the 1870's, IAHS, 193, 127-135, 1990.

Cogley, J. G.: A more complete version of the World Glacier Inventory, Ann. Glaciol., 50, 32-38, 2009a.

Cogley, J. G.: Geodetic and direct mass-balance measurements: comparison and joint analysis, Ann. Glaciol., 50, 96-100, $2009 \mathrm{~b}$.

Delworth, T. L., Broccoli, A. J., Rosati, A., Stouffer, R. J., Balaji, V., Beesley, J. A., Cooke, W. F., Dixon, K. W., Dunne, J., Dunne, K. A., Durachta, J. W., Findell, K. L., Ginoux, P., Gnanadesikan, A., Gordon, C. T., Griffies, S. M., Gudgel, R., Harrison, M. J., Held, I. M., Hemler, R. S., Horowitz, L. W., Klein, S. A., Knutson, T. R., Kushner, P. J., Langenhorst, A. R., Lee, H.-C., Lin, S.-J., Lu, J., Malyshev, S. L., Milly, P. C. D., Ramaswamy, V., Russell, J., Schwarzkopf, M. D., Shevliakova, E., Sirutis, J. J., Spelman, M. J., Stern, W. F., Winton, M., Wittenberg, A. T.,
Wyman, B., Zeng, F., and Zhang, R.: GFDL's CM2 Global Coupled Climate Models. Part I: formulation and simulation characteristics, J. Climate, 19, 643-674, 2006.

Flato, G. M.: The third generation coupled global climate model (CGCM3), available at: http://www.cccma.ec.gc.ca/models/ cgcm3.shtml, 2005.

Furevik, T., Bentsen, M., Drange, H., Kvamsto, N., and Sorteberg, A.: Description and evaluation of the Bergen climate model: ARPEGE coupled with MICOM, Clim. Dynam., 21, 27-51, 2003.

Gordon, C., Cooper, C., Senior, C. A., Banks, H. T., Gregory, J. M., Johns, T. C., Mitchell, J. F. B., and Wood, R. A.: The simulation of SST, sea ice extents and ocean heat transports in a version of the Hadley Centre coupled model without flux adjustments, Clim. Dynam., 16, 147-168, 2000.

Gregory, J. M. and Oerlemans, J.: Simulated future sea-level rise due to glacier melt based on regionally and seasonally resolved temperature changes, Nature, 391, 474-476, 1998.

Jungclaus, J. H., Keenlyside, N., Botzet, M., Haak, H., Luo, J. J., Latif, M., Marotzke, J., Mikolajewicz, U., and Roeckner, E.: Ocean circulation and tropical variability in the coupled model ECHAM5/MPI-OM, J. Climate, 19, 3952-3972, 2006.

K-1 model developers: K-1 coupled model (MIROC) description, Tech. rep. 1, Center for Climate System Research, University of Tokyo, 2004.

Leclercq, P. W., Oerlemans, J., and Cogley, J. G.: Estimating the Glacier Contribution to Sea-Level Rise for the Period 18002005, Surv. Geophys., doi:10.1007/s10712-011-9121-7, in press, 2011.

Lucarini, L. and Russell, G. L.: Comparison of mean climate trends in the northern hemisphere between National Centers for Environmental Prediction and two atmosphereocean model forced runs, J. Geophys. Res., 107(D15), 4269, doi:10.1029/2001JD001247, 2002.

Meehl, G. A., Covey, C., Delworth, T., Latif, M., McAvaney, B., Mitchell, J. F. B., Stouffer, R. J., and Taylor, K. E.: The WCRP CMIP3 multi-model dataset: A new era in climate change research, B. Am. Meteorol. Soc., 88, 1383-1394, 2007a.

Meehl, G. A., Stocker, T. F., Collins, W. D., Friedlingstein, P., Gaye, A., Gregory, J., Kitoh, A., Knutti, R., Murphy, J., Noda, A., Raper, S., Watterson, I., Weaver, A., and Zhao, Z.-C.: Global climate projections, in: Climate Change 2007: The Physical Science Basis. Contribution of Working Group I to the Fourth Assessment Report of the Intergovernmental Panel on Climate Change, edited by: Solomon, S., Qin, D., Manning, M., Chen, Z., Marquis, M., Averyt, K. B., Tignor, M., and Miller, H. L., Cambridge University Press, Cambridge, UK and New York, NY, USA, 2007b.

Meier, M. F., Dyurgerov, M. B., Rick, U. K., O’Neel, S., Pfeffer, W. T., Anderson, R. S., Anderson, S. P., and Glazovsky, A. F.: Glaciers dominate eustatic sea-level rise in the 21st century, Science, 317, 1064-1067, 2007.

Nakicenovic, N. and Swart, R. (Eds.): Emission scenarios, Cambridge University Press, Cambridge, UK, 2000.

National Snow and Ice Data Center: World glacier inventory, World Glacier Monitoring Service and National Snow and Ice Data Center/World Data Center for Glaciology, Boulder, CO, 1999, updated 2009.

Oerlemans, J.: Modelling of glacier mass balance, in: Ice in the 
climate system, Nato ASI Ser. I 12, 1993.

Oerlemans, J.: Quantifying global warming from the retreat of glaciers, Science, 264, 243-245, 1994.

Oerlemans, J. and Fortuin, J. P. F.: Sensitivity of glaciers and small ice caps to greenhouse warming, Science, 258, 115-117, 1992.

Oerlemans, J. and Reichert, B. K.: Relating glacier mass balance to meteorological data by using a seasonal sensitivity characteristic, J. Glaciol., 46, 1-6, doi:10.3189/172756500781833269, 2000.

Oerlemans, J., Dyurgerov, M., and van de Wal, R. S. W.: Reconstructing the glacier contribution to sea-level rise back to 1850 , The Cryosphere, 1, 59-65, doi:10.5194/tc-1-59-2007, 2007.

Paterson, W. S. B.: The Physics of Glaciers, 3rd edn., Pergamon, Oxford, U. K., 1994.

Pfeffer, W. T., Harper, J. T., and O’Neel, S.: Kinematic constraints on glacier contributions to 21st-century sea-level rise, Science, 321, 1340-1343, doi:10.1126/science.1159099, 2008.

Radić, V. and Hock, R.: Regional and global volumes of glaciers derived from statistical upscaling of glacier inventory data, J. Geophys. Res., 115, F01010, doi:10.1029/2009JF001373, 2010.

Radić, V. and Hock, R.: Regionally differentiated contribution of mountain glaciers and ice caps to future sea-level rise, Nat. Geosci., 4, 91-94, doi:10.1038/NGEO1052, 2011.

Randall, D. A., Wood, R. A., Bony, S., Colman, R., Fichefet, T., Fyfe, J., Kattsov, V., Pitman, A., Shukla, J., Srinivasan, J., Stouffer, R. J., Sumi, A., and Taylor, K. E.: Climate models and their evaluation, in: Climate Change 2007: The Physical Science Basis. Contribution of Working Group I to the Fourth Assessment Report of the Intergovernmental Panel on Climate Change, edited by: Solomon, S., Qin, D., Manning, M., Chen, Z., Marquis, M., Averyt, K. B., Tignor, M., and Miller, H. L., Cambridge University Press, Cambridge, UK and New York, NY, USA, 2007.

Raper, S. C. B. and Braithwaite, R. J.: Low sea level rise projections from mountain glaciers and icecaps under global warming, Nature, 439, 311-313, 2006.

Schmidt, G. A., Ruedy, R., Hansen, J. E., Aleinov, I., Bell, N., Bauer, M., Bauer, S., Cairns, B., Canuto, V., Cheng, Y., Del Genio, A., Faluvegi, G., Friend, A. D., Hall, T. M., Hu, Y., Kelley, M., Kiang, N. Y., Koch, D., Lacis, A. A., Lerner, J., Lo, K. K., Miller, R. L., Nazarenko, L., Oinas, V., Perlwitz, J., Rind, D., Romanou, A., Russell, G. L., Sato, M., Shindell, D. T., Stone, P. H., Sun, S., Tausnev, N., Thresher, D., and Yao, M. S.: Present day atmospheric simulations using GISS ModelE: Comparison to in-situ, satellite and reanalysis data, J. Climate, 19, 153-192, 2006.
Schotman, H. H. A.: Shallow-Earth rheology from glacial isostasy and satellite gravity, Ph.D. thesis, TU Delft, 2008.

Slangen, A. B. A., Katsman, C. A., van de Wal, R. S. W., Vermeersen, L. L. A., and Riva, R. E. M.: Towards regional projections of twenty-first century sea-level change based on IPCC SRES scenarios, Clim. Dynam., doi:10.1007/s00382-011-10576, in press, 2011.

Trenberth, K. E., Jones, P., Ambenje, P., Bojariu, R., Easterling, D., Tank, A. K., Parker, D., Rahimzadeh, F., Renwick, J., Rusticucci, M., Soden, B., and Zhai, P.: Observations: surface and atmospheric climate change, in: Climate Change 2007: The Physical Science Basis. Contribution of Working Group I to the Fourth Assessment Report of the Intergovernmental Panel on Climate Change, edited by: Solomon, S., Qin, D., Manning, M., Chen, Z., Marquis, M., Averyt, K. B., Tignor, M., and Miller, H. L., Cambridge University Press, Cambridge, UK and New York, NY, USA, 2007.

Van de Wal, R. S. W. and Wild, M.: Modelling the response of glaciers to climate change by applying volume-area scaling in combination with a high resolution GCM, Clim. Dynam., 18, 359-366, 2001.

Washington, W. M., Weatherly, J. W., Meehl, G. A., Semtner Jr., A. J., Bettge, T., Craig, A., Strand Jr., W., Arblaster, J., Wayland, V., James, R., and Zhang, Y.: Parallel climate model (PCM) control and transient simulations, Clim. Dynam., 16, 755-774, 2000.

Yukimoto, S. and Noda, A.: Improvements of the Meteorological Research Institute Global Ocean-atmosphere Coupled GCM (MRI-CGCM2) and its climate sensitivity, Tech. rep. 10, NIES, Japan, 2002.

Zuo, Z. and Oerlemans, J.: Contribution of glacier melt to sea-level rise since AD 1865: a regionally differentiated calculation, Clim. Dynam., 13, 835-845, 1997. 